\title{
Diagnóstico de la infección urinaria en Pediatría
}

DR. GASTON ZILLERUELO B,"

La infección urinaria continúa siendo el gran camaleón de la patología renal del niño y así to parecen demostrar las innumerables publicaciones sobre el problema diagnóstico de esta infección en pediatría. A esta dificultad diagnóstica contribuyen sin duda la variabilidad del cuadro clínico, la ausencia de signos típicos de Infección Urinaria y la dificultad de obtener examen de orina representativo en especial en la primera infancia precisamente donde ocurren la mayor parte de las I. U., dejando muchas veces secuelas imprevisibles en el tejido renal como punto de partida de una Pielonefritis crónica. Todo esto sin considerar la importancia de la Infección Urinaria asintomá tica demostrada por Kunin y otros en niñitas en edad escolar.

Cabe plantearse entonces en qué niños la clínica nos permite sospechar e ir a la pesquisa del diagnóstico de Infección Urinaria.

De acuerdo con nuestra experiencia la $\mathbf{I}$. U. en el niño tiene las siguientes características propias de cada grupo de edad encontradas en 200 casos estudiados por nosotros en el Hospital Luis Calvo Mackenna (ver Figura I Síntomas clínicos en la I. U.). En el grupo de lactantes los síntomas se orientan a cuadros febriles o trastornos gastrointestinales, $y$ en el niño mayor en cambio, predominan los síntomas subjetivos referidos al árbol urinario.

Sin embargo, el polimorfismo del cuadro clínico hace que el diagnóstico clínico sea sólo presuntivo y deba ir siempre confirmado por el examen de orina y fundamentalmente por el estudio bacteriológico con identificación y cuantificación del agente bacteriano ya que un porcentaje importante de pacientes con síntomas sugerentes de I. U. no presentan bacteriuria significativa (Brumfitt)

\footnotetext{
- Departamento de Nefrología. Hospital L. Calvo-Mackenna.
}

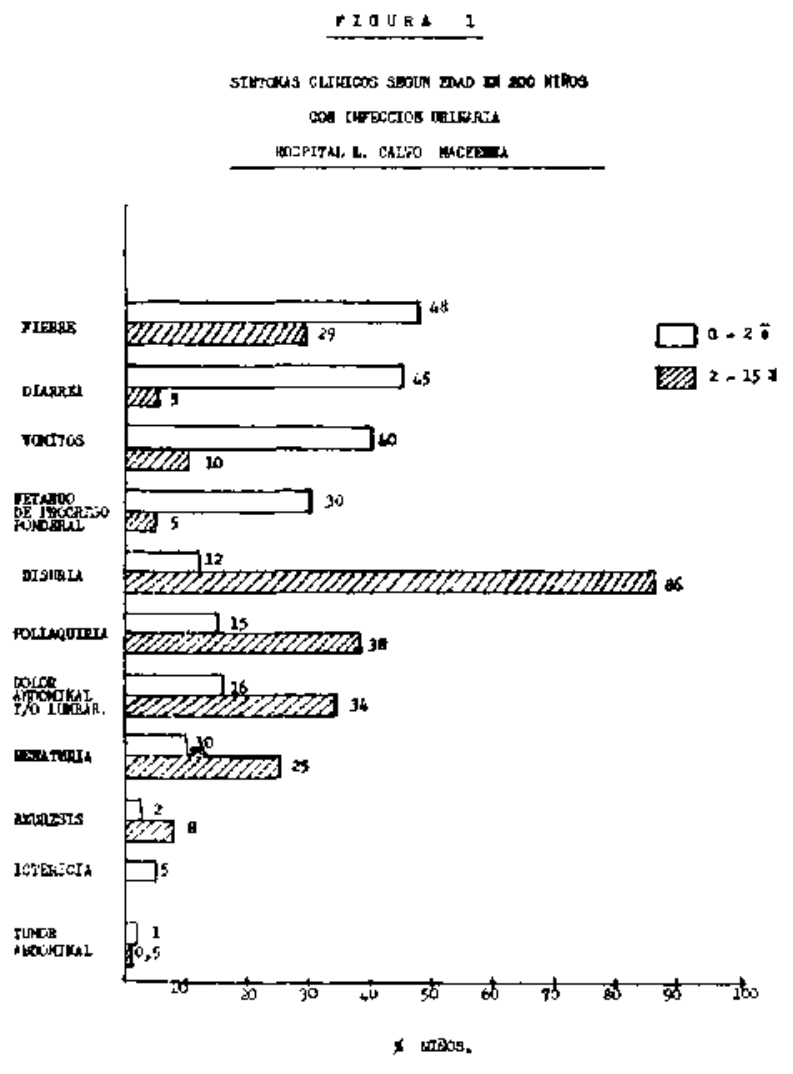

y a la inversa niños con $\mathbf{I}$. U. bien establecida no presentan síntomas propios del aparato urínario (recién nacidos, lactantes, niñitas en edad escolar).

La importancia del recuento bacteriano se debe a la distinción entre lo que es bacteriuria significativa y contaminación como ya han señalado Kass y otros investigadores. En orinas miccionales asépticas consideramos como límite significativo sobre $100.000 \mathrm{col} . / \mathrm{ml}$, y en orinas obtenidas por 


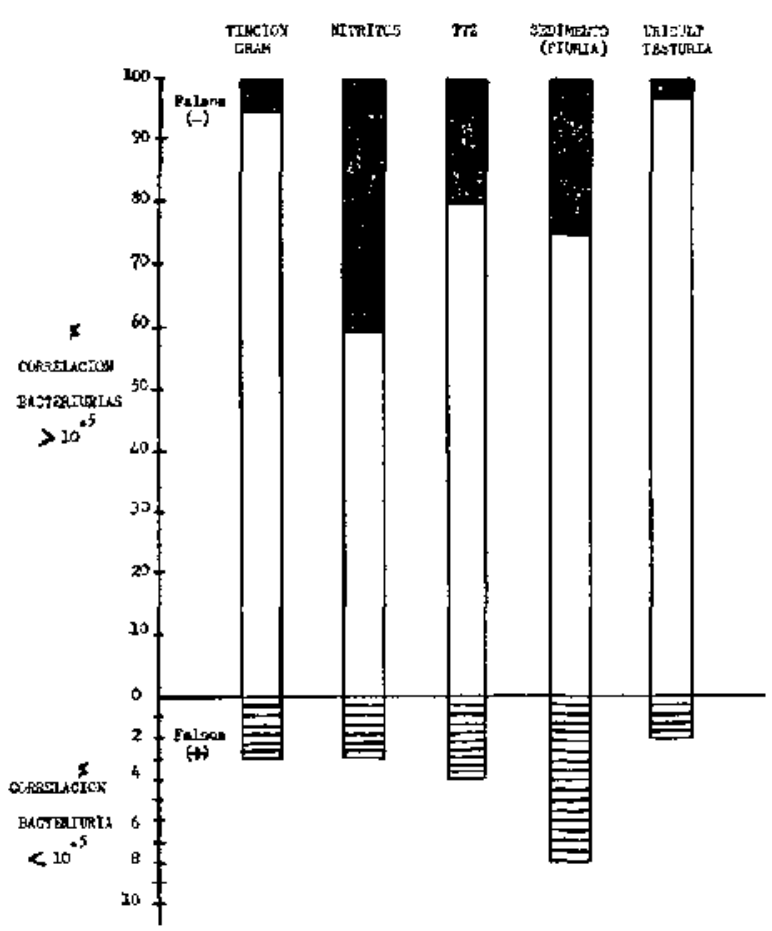

Figura N 2. - Métodu de orientación diagnóstiça en bacteriuria.

Punción vesical suprapúbica cualquier recuento bacteriano. En pacientes asintomáticos se neccsitan por to menos 2 recuentos sobre 10.000 para certificar el diagnóstico. La estimación del número de bacterias ha llevado a desarrollar métodos rápidos y sencillos de orientación o de detección de Infección Urinaria en granes grupos de población. Para ellos se han usado el examen microscópico de la orina con o sin tinción, reacciones enzimáticas o bien medios de cultivo inmediato de la orina en láminas apropiadas (Figura II Método de orientación Diagnóstica en Bacteriurias).

Como se aprecia, la Tinción de Gram en orinas no centrifugadas y los métodos de cultivo rápido en láminas (Uricult.) aparecen como los métodos de mejor correlación con el examen bacteriológico (screcning test). El hallazgo de piuria ( +5 leuc/campo) en el sedimento es un buen método de aproximación, ya que da en nuestra experiencia, cerca de un $75 \%$ de correlación en muestras bien tomadas.

La interpretación por parte del clínico del examen bacteriológico de orina nos parece muy importante pucs siempre debe recordarse que existen falsos resultados $(+)$ por mala toma o manejo de la muestra de orina, y falsos resultados (-) por medicación antibiótica anterior, infecciones obstructivas cerradas, gérmenes en variantes $L$ descritas en I. U. recurrentes, y no cultivables en medios corrientes, antisépticos en el aseo genital previo, ctc. . . Una vez hecho el diagnóstico de Infec- cción de las vías urinarias cabe plantearse la siguientc interrogante. ¿Hay compromiso infeccioso renal, es decir se trata de una Pielonefritis verdadera o no? El diagnóstico de bacteriuria significativa no implica si la infección está limitada al tracto urinario inferior o compromete al riñón, hecho de gran importancia pronóstica y de enfoque terapéutico en estos pacientes.

Muchos métodos se disponen para localizar la I. U. pero en la actualidad no existe un método exclusivo que sea el ideal, ya que ninguno reúne el alto grado de confiabilidad y sencillez requeridad. Los más estudiados se resumen en la tabla Nọ 1 .

De ellos el más aplicado es la determinación de anticuerpos contra el agente infectante. Desde las experiencias realizadas por Needell y Neter y más recientemente por Andersen se conoce el hecho de que la I. U. causada por E. Coli puede inducir una respuesta de anticuerpos en el suero del paciente medible por técnicas de Hemaglutinación. Esta respuesta inmunológica se produciría sólo en aquellos casos con Pielonefritis como lo demuestra el siguiente cuadro la correlación entre el cuadro clínico, incluyendo pruebas de concentración y de examen pielocistográfico y el hallazgo de títulos de anticuerpos en el suero de 30 niños con infección urinaria estudiados en nuestro Hospital (Tabla 2). Cuando los parámetros clínicos, radiológicos y funcionales de riñón planteaban Pielonefritis se encontró un $88 \%$ con anticuerpos séricos anti-coli elevados sobre lo normal. A la inversa, en I. U. baja no se encontraron anticuerpos.

$$
\text { T A B L A } N^{\circ} 1
$$

METODOS DE LOCALIZACION DE LA INFECCION EN EL TRACTO URINARIO (*)

\section{Directos}

1) Cateterización ureteral (Ex. Bacteriológico orina ureteral).

2) Biopsia renal

(Ex. histológico y bacteriológico)
Indirectos

1) Anticuerpos séricos (Hemaglutinación cepa urinaria)

2) Prueba de concentración máxima de la otina.

3) Excreción urinaria de enzimas.

4) Estimulación con Prednisolona.
* Brumfitt (1969).

Esta buena correlación entre títulos de anticuerpos elevados y compromiso renal de la infección se ha visto corroborada con los estudios bacteriológicos en orinas ureterales y en tejido renal (Tabla 3) y con pruebas funcionales como la ca- 
CORRELACION DEL CUADRO CLINICO DE LA INFECCION URINARIA Y EL TITULO DE ANTICUERPOS ANTI-COLI. HOSPITAL LUIS CALVO MACKENNA

\begin{tabular}{lcll}
\hline Cuadro clintico & \multirow{2}{*}{$N^{0}$ niños } & \multicolumn{2}{c}{$\begin{array}{c}\text { Anticterpos anti-coli } \\
\text { (hemaglutinación) }\end{array}$} \\
& & $\langle 1 / 64$ & $>14 / 16$ \\
\hline Pielonefritis (*) & 16 & $2 / 16$ & $14 / 16$ \\
& & $(12 \%)$ & $(88 \%)$ \\
I. U. Baja & 6 & $6 / 6$ & $0 / 6$ \\
& & $(100 \%)$ & $(0 \%)$ \\
Cuadro Intermedio & 8 & $4 / 8$ & $4 / 8$ \\
& & $(50 \%)$ & $(50 \%)$ \\
Controles & 10 & $10 / 10$ & $0 / 10$ \\
& & $(100 \%)$ & $(0 \%)$ \\
\hline
\end{tabular}

(*) Osm. U. máx. \6/8.

Pielocistografía alterada $6 / 9$.

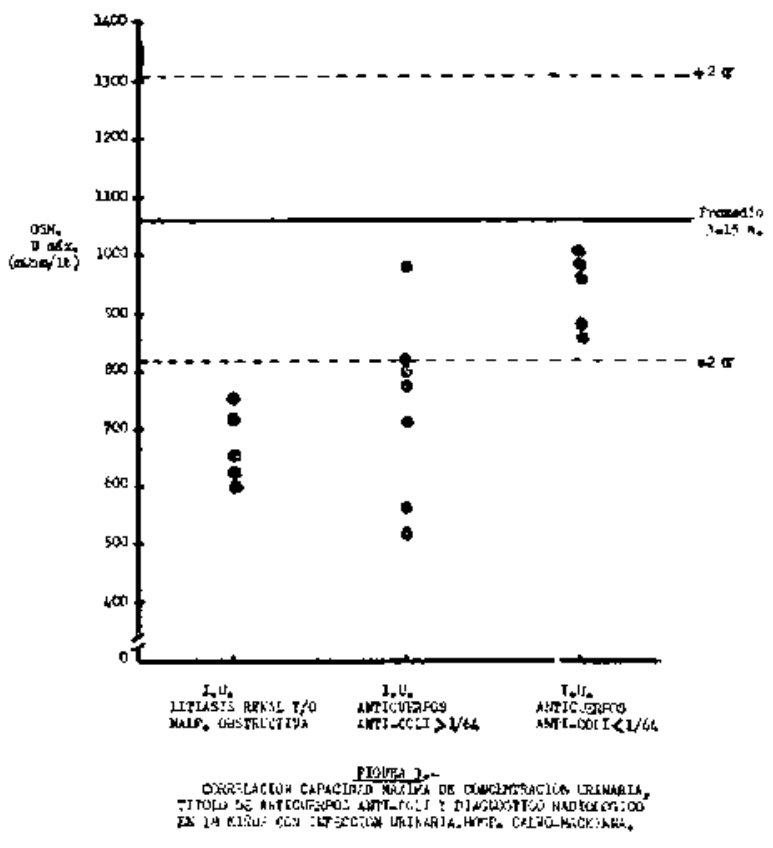

CORRELACION ENTRE EL TITULO DE ANTI. CUERPOS Y EL EXAMEN DE TEJIDO RENAL $Y Y$ ORINA URETERAL **

\begin{tabular}{lcc}
\hline $\begin{array}{l}\text { Examen tejido renat } \\
\text { y orina upeteral }\end{array}$ & $\begin{array}{c}\text { No pacientes } \\
\text { Título anticuer- }\end{array}$ & $\begin{array}{c}\text { pos elevados } \\
1 / 320\end{array}$ \\
\hline Cultivo e histología $(+)$ & $8 / 41$ & $7 / 8$ \\
Cultivo e histología (-) & $18 / 21$ & $0 / 18$ \\
Orina ureteral (+) & $6 / 22$ & $6 / 6$ \\
Orina ureteral (一) & $16 / 22$ & $0 / 16$ \\
\hline$*$ Percival (1964). & & \\
$* *$ Hewstone (1970).
\end{tabular}

pacidad máxima de coneentración urinaria (Figura 3). Esta capacidad depende en gran medida de la función tubular de aquella porción ubicada más cerca de la médula renal que como se sabe es la más infectada por la inflamación en la pielonefritis. Así se ve que en aquellos casos con Infección Urinaria ascciada a elcmentos que sugieren compromiso renal (Litiasis renal, obstrucción, anticuerpos elevados) la capacidad máxima de concentrar la orina era inferior a $800 \mathrm{mOsm}$./1t. Entre las ventajas del estudio de anticuerpos séricos en la I. U. aparte de precisar el grado de invasión tisular, permite determinar el agente causal cuando hay infecciones mixtas en que un bacterio es contaminante, diferenciar entre reinfección y recaída en I. U. a repetición, permite valorar el significado de bacteriurias mínimas persistentes, y tiene un interés pronóstico, ya que los fracasos terapéuticos serían más frecuentes cuando hay títulos de anticuerpos elevados (Brumfitt, Kass).

Una vez resuelto el problema diagnóstico y de localización de la Infección Urinaria quedan todavía por resolver muchas otras incógnitas que scrán comentadas en otros correlatos. 